\title{
Las dignidades como nuevas epistemologías liberadoras-descolonizadoras del y los Trabajos Sociales otros
}

Carlos Mejías Sandia

Doctor en Sociología (Universidad

Autónoma de Chile)

Correo: cmejiass@yahoo.com

Pablo Suárez Manríquez

Magister en Políticas Sociales (Universidad

Tecnológica Metropolitana)

Correo: psuarez@utem.cl 
Resumen

La positivización de las ciencias sociales y del Trabajo Social ha llevado a establecer un parámetro rígido de lo que entendemos por ciencia, ha despersonalizado la investigación e impuesto una supuesta "objetividad pura" de lo observado creando los supuestos "objeto de estudio" como elemento distintivo de cada ciencia en particular. En el marco de la investigación "Las dignidades descolonizadas como nuevas praxis para el Trabajo Social”, donde apuntamos estas reflexiones iniciales sobre la idea de la dignidad humana como necesidad de estudio deslocalizado para la constitución de unas otras praxis en Trabajo Social, que, de alguna manera, nos permitan apuntar a su desconceptualización, con el objetivo de ayudar a posicionar su vivencia como un elemento central para nuevas epistemologías y nuevas formas de entender y vivir el trabajo social.

Palabras clave epistemologías, dignidades, trabajo social, decolonización

\section{Abstract}

The positivization of the social sciences and Social Work has led to establishing a rigid parameter of what we understand by science, it has depersonalized research and imposed a supposed "pure objectivity" of what is being observed creating the alleged "object of study" as a distinctive element of each particular science. Within the framework of the research "Decolonized dignities as new praxis for Social Work", we point out some initial reflections on the idea of human dignity as a need for delocalized study for the constitution of some other Social Work praxis that allow us to point to its deconceptualization, with the aim of helping to position its experience as a central element for new epistemologies and new ways of understanding and living social work.

Key Word

epistemologies, dignities, social work, decolonization 


\section{Introducción}

Las ciencias sociales y también el Trabajo Social, particularmente el suramericano, han desarrollado diversas interpretaciones de la realidad, adoptando la producción intelectual y el marco epistémico de la colonialidad eurocentrada. Cada una de esas teorías, más complejas, homogenizantes, emancipatorias y universalistas, paradojalmente se presentan más delimitadas y atomizadas y desvinculadas de las realidades particulares. En palabras simples, los modelos disciplinarios y sus variantes sociales están agotadas en la forma y el fondo para leer e interpretar/explicar la realidad. Y más que interpretar la realidad se han transformado en aparatos de poder que disfrazan procesos operativos de vigilancia, regulación, disciplinamiento y control social, se relacionaban directamente con la colonialidad del poder, del saber, del ser, del estar y del vivir. Son estos aspectos sobre el cual versan unos de los aportes más importantes de los discursos críticos latinoamericano en sus diferentes versiones, marxismo crítico, teoría de la dependencia, proyecto descolonial y epistemologías del sur. Son discursos que subrayan la importancia de una relectura de la inserción de América Latina a la realidad de la modernidad capitalista y de cómo ello se refleja en las ciencias sociales y del papel que deben jugar dentro de estas nuevas realidades.

Sin embargo, se han instalado en las ciencias sociales, y en Trabajo Social, discursos seudocríticos, seudoemancipadores que tienden a confundir y a fragmentar. Discursos que apelando a una criticidad transformadora sólo destacan el carácter colonizador y de sometimiento al capitalismo moderno, cuya producción y reproducción no puede efectuarse sin desplegar una lógica colonizadora dirigida a explotar recursos, fuerzas de trabajo e instituir poderes, saberes y vivires; así mismo, a subrayar que detrás de esa lógica colonizadora existió y existe también una lógica orientada a instituir saberes hegemónicos, bajo la presunción de saberes modernos y civilizatorios. Imponer culturas orientadas también a instituir simbólicamente la realidad colonial de América Latina. Esos discursos, que se han naturalizado como "oficiales" son los que dominan, en gran parte, la 
producción de conocimientos en las ciencias, y especialmente, en las ciencias sociales.

La crítica no es sólo interna a la matriz epistemológica positivista en la que se inspiran y moldean las ciencias sociales, aspecto sobre lo cual han insistido las diferentes versiones del pensamiento crítico europeo. Se trata de una crítica, si se quiere externa, relacionada con su pretensión de universalidad, que niega las especificidades de realidades diferentes a su lugar histórico cultural determinado, invisibilizando o negando la existencia o la posibilidad de otros saberes, de otras formas de habitar el mundo, de otras formas de entenderlo y donde las diversas formas de constituirse que ha tenido el Trabajo Social, solo han acogido miradas parciales o leves de mirar la realidad de otras maneras, incluido el proceso de reconceptualización que se suponía más crítico y con un fin emancipador.

Las ciencias sociales y el trabajo social siempre han declarado estar del lado de los oprimidos, de los subalternos, de los pobres, está arraigado en toda una trayectoria, en toda una tradición, en todas unas dinámicas que comprometen al ser en toda su plenitud, no sólo en su razón, en su pensamiento, sino también en sus emociones, en sus afectos, en sus saberes, en su relación con el universo, la Pacha o Mapu, como sostienen quechuas y mapuche. La intelectualidad en América latina ha sido presa de su propia alienación, cautiva de una estructura y forma de pensar, de concebir y traspasar la realidad y no ha sido capaz de desprenderse del lastre de la colonialidad, es más, le ha entregado un estatus superlativo y naturalizado de tal manera que llevados a su cuestionamiento cierran filas en su defensa desde postulados políticamente geo-referenciados como euro-epistémicos. Esto situación ha generado un canon irredargüible en la reflexión intelectual crítica latinoamericana, al igual que en Europa, ha redundado en una disciplinarización, en un control, una suerte de hegemonía de ese pensamiento nomotético/positivista, cuantificador, racionalista, cientificista, abstracto, instrumental que marca una distancia entre sujeto-objeto y una distancia entre conocimiento y realidad considerada simplemente como objetos de conocimiento. La positivización de las ciencias sociales y el Trabajo Social ha llevado a establecer un 
parámetro rígido de lo que se entiende por ciencia, ha despersonalizado la investigación, ha inventado e impuesto una supuesta "objetividad pura" de lo observado y ha creado los mal llamados "objeto de estudio" como elemento distintivo de cada ciencia en particular.

Es en este marco donde pretendemos apuntar unas reflexiones iniciales sobre la idea de la dignidad humana como necesidad de estudio deslocalizado y no como "objeto de estudio", que de alguna manera nos permitan apuntar a su desconceptualización, así como ayudar a posicionar su vivencia como un elemento central para nuevas epistemologías y formas de entender y vivir el trabajo social.

\section{La colonización epistemológica como realización acrítica}

Vivimos en un mundo donde lo central es lo superfluo, lo enajenante, lo vano y adquiere el carácter de esencial ${ }^{49}$, se transforma en el eje vital que mueve la humanización y estamos tan convencidos de aquello que todo lo miramos desde esa óptica y si algo tiene un espesor crítico, lo desechamos o lo vaciamos de su contenido. Por lo mismo, la experiencia y el conocimiento de lo real, en consecuencia, se reducen a lo aceptado por los parámetros clasificatorios de la razón instrumental-eurocentrada, más allá de los cuales no hay experiencias posibles de otros saberes más allá de los sistemas dicotómicos de ideas consideradas la única y verdadera realidad. Estas formas de conocimiento alternativas son simplemente ignoradas, marginadas o suprimidas lo que nos lleva a la reducción de la comprensión del mundo unívoco. Se reduce la experiencia comunicable a mera «experiencia mecánica», repetitiva y cuantificable, auspiciada en gran parte por el desarrollo del capitalismo, y particularmente, del neoliberalismo y la conquista del poder social y económico por parte de

49 La existencia empírica desaparece por completo, y la esencia no es «lo dado»; de lo que se trata es, precisamente, de construir la realidad de la esencia al margen de la existencia empírica. Ello implica la tendencia de los observadores a comprender las categorías sociales como si ellas fueran naturales. Los individuos tienden a considerar la pertenencia a una categoría social como el reflejo de una identidad única y real. 
la burguesía, lo transformó en poder hegemónico que han llevado a una situación de pobreza antropológica, de pérdida progresiva de lo humano, marcada por el desperdicio de valiosos universos simbólicos y de sentido, dotados de memoria identitaria y cultural, instituciones, prácticas sociales y sabidurías más allá de las epistemologías.

La civilización científico-técnica occidental en la que estamos sumergidos ha llevado a muchísimas personas a creer en la eficacia de las instrumentaciones puramente técnicas. Hemos aprehendido que la quimera de lo real es la realidad de la exclusión, de la marginación, y han buscado deslumbrarnos por las conquistas de lo tangible, volviéndose insensibles y ciegos frente a la pluriversalidad del mundo, frente a la multiplicidad de sentires y conoceres. Nos ha convencido, una y otra vez que todo lo posible es moralmente lícito, con tal de que sea eficaz para acumular riqueza y disfrutar del bienestar a cualquier precio: "un mercado volcado a la búsqueda de la "eficacia, el consumo, el lucro y el progreso, que vienen poniendo en jaque nuestra propia existencia en la Tierra" (Adao, 2011:58). Lo devastador de esta forma de desarrollo de las ciencias sociales y el Trabajo Social es que esta misma matriz es impuesta en el plano de lo humano. Las políticas neoliberales, destruyen la vida y riqueza cultural de pueblos, comunidades, personas que quedan en medio camino, entre un "ser" en el consumo y un no ser o un ser excluido y pauperizado que requiere ser incluido en las lógicas de funcionamiento del mercado. Los niños de la calle, los niños soldados, las mujeres, los campesinos empobrecidos, lxs trabajadorxs explotadxs, pueblos originarios, diversidad sexual, inmigrantes, refugiadxs, discapacitadxs. Todas y todos son las y los grandes perdedores, humillados, oprimidos, olvidados, despojados de su pluridignidades y sus narrativas nativas. Ellos/ellas han sido enterrados bajo las historias de sus historias, asimiladas sus identidades a la única verdad identitaria imperante y homogeneizantes donde sus sentimientos, esperanzas no tienen correlato monetario y sólo sirven si producen o contribuyen a la productividad. Aquí surge la principal interrogante ¿dónde y cómo se sitúa el Trabajo Social?, ¿cómo rompe con esta extensa colonialidad para situarse desde las complejas y diversas pobrezas del campo y la ciudad?, ¿cómo reflexio- 
na sobre "igualdad", si mientras más pensamos y sentimos la "diferencia" se hace más fuerte?

Somos conscientes que la colonialidad eurocentrada del poder (Quijano, 2014), comienza con una estrategia de colonización de los discursos de la "disciplina" del Trabajo Social a través de la necesaria revalidación de este discurso por parte del régimen de verdad de las Ciencias Sociales. Es el texto y la lógica racional colonizada de las Ciencias Sociales la que va a legitimar como verdadero o no solo el discurso del Trabajo Social sino fundamentalmente el destino y sentido de su acción, y en general de muchos de los discursos de otras ciencias. La lógica colonizada que subyace a las reflexiones discursivas de estas Ciencias Sociales delimitan y controla las potenciales formaciones activo-discursivas que propone el Trabajo Social y que están dados, por el hecho de que el discurso del Trabajo Social se encuentra en un lugar estratégico dentro de la construcción de las relaciones sociales y políticas en la sociedad; ya que su práctica profesional, su lugar agonístico, es en la inter-facialidad de las personas y sus familias o en las comunidades que forman la proposición de verdad que intenta "intervenir", manipular y construir la subjetividad de los miembros de la sociedad y ante lo cual lo reduce al espacio operativo y/o policial como lo plantea Guattari (1998). Por ende, el Trabajo Social y la territorialidad de su acción-reflexión es un punto de inflexión estratégico que se puede utilizar cuando se visualizan "grietas" para abrir y establecer las "luchas por las dignidades" y/o por multivariar las verdades. Es sobre este discurso del poder y por ende el de la construcción de política, uno de los lugares que está más sometido a vigilancia y a procedimientos de control y disciplinamiento. Conocemos que una forma de control externo que se ejerce sobre las acciones y los discursos es la proliferación de los mismos. Las multiplicidades de discursos sobre el original logran que, a partir de la repetición, ese discurso se disperse, sus efectos se enmascaren, su voluntad de realidad se evite. Logrando así que la participación y conocimiento se conviertan en un elemento de forma y metodológico más que de fondo político e ideológico, como es el caso de 
la "sistematización" al enfrentar el discurso de las Ciencias Sociales colonizadas.

De esta manera se le quita a la participación lo que esta denuncia en relación con el poder y el saber. Separando el conocimiento que subyace a la participación en el ejercicio efectivo del poder. La participación desde el punto de vista es purificada en el discurso de la ciencia colonial, se le borra su sentido político y su intención de cambio civilizatorio, limitándola a un discurso instrumental y depurado quedando, por ejemplo, la sistematización reducida a una narración de hechos incapaces de levantar teorías. Por ello este discurso de saber/poder/ser de las Ciencias Sociales colonizadas debe formar parte del propio discurso del Trabajo Social bajo el pretexto de que así el Trabajo Social logra cientificidad. Cuando en realidad solo se trata de normalizarlo, de funcionalizarlo e instrumentalizarlo reduciéndolo a su mínima expresión científica. Es en estos contextos, que asistimos a la aparición de imperativos claros para que las praxis de los Trabajos Sociales no puedan hablar sobre el poder. Así se crean toda una gama de discursos, acciones, metodologías que nos dicen cómo sistematizar o cómo hacer que la palabra de los otros (los excluidos, los marginados), puedan ser palabra de realidad para las ciencias. Nos dicen como quitarles la violencia, la agresividad, la voluntad de poder que esos discursos de las gentes tienen y por el cual quieren entrar en discusión con los saberes existentes. Los y el Trabajo Social contemporáneo en Latinoamérica ha caído en la trampa de la mirada dicotómica para entender, explicar y accionar en la realidad (subjetividad/objetividad, regulación/cambio, emancipación/estatus quo), y ello, ha sido trasladado a las acciones profesionales abandonando la criticidad de sus accionares y obviando y olvidando la pluralidad de realidades, de problemáticas y, sobre todo, a las personas, a mujeres y hombres que buscan resolver sus conflictividades y exclusiones. Asumimos como dogma y única alternativa posible que los trabajadores sociales que son empleados por el Estado se encuentren sujetos a una rígida regulación de su práctica (Munro, 2011). Es más, las y los trabajadores sociales que deciden romper con esta inercia son considerados activistas y no necesariamente como profesionales (Lavalette e Ioakimides, 
2011). Visibilizamos y denunciamos el discurso hegemónico legitimador subyacente al orden vigente que proclama valores que no son "dignos" para la realización plena de los "nadie" 50 . Hegemonía que antepone el tener y el ser sobre el estar, donde se privilegian valores individuales, incentivando la lógica del emprendimiento empresarial y competitividad, el egoísmo y el cambio de valores que, desde otra mirada axiológica, a las familias en la vida cotidiana les entregaba una cierta cohesión y humanización. La dignidad la esgrimimos como bandera de la humanidad, pero esa dignidad en la civilización actual está vacía, no significa ni simboliza nada, es la dignidad del capitalismo, del que posee bienes, del que no es totalmente consciente de su explotación laboral y personal, la dignidad de lo individual, de la dignidad que destroza lo colectivo-comunitario.

Si bien es cierto que el Trabajo Social Latinoamericano tiene una vasta trayectoria en promoción, organización y reconstrucción del tejido social y de apoyo a la generación de movimientos sociales, lo cual es difícil de imaginar por los trabajadores sociales de Europa (Alhaj et al, 2013), creemos que en nuestro continente éste ha perdido el sustrato de la acción y su contenido político, así como su proyecto político. Hoy no basta establecer que ciertas premisas discursivas tengan el estatus de verdad y fundamento para la acción, sino el peligro radica en que esos "fundamentos verdaderos" nos alejan de cuestionarnos nuestro quehacer constantemente. Dada esta situación, el riesgo es muy grande, porque en esas verdades fundacionales de la acción naturalizamos las amenazas al mundo liberal occidental, con y desde sus alternativas euro céntricas, las cuales se nos presentan como "lo único que hay". Y peor aún, lo único que puede existir. Incluso si pensamos en clave de transformación de ese mundo, aparece allí de un modo enfático, creíble, posible.

En el ámbito educativo y posteriormente en el profesional se aprende sólo a memorizar y resumir, con costo interpretar, traducir y evaluar el valor y la utilidad de todo tipo de experiencias, como de toda

50 Hacemos referencia a Eduardo Galeano y su poema Los Nadie, publicado en 1989 en el "libro de los abrazos". 
epistemología, desde el conocimiento científico social eurocentrado, sin sospechar siquiera la necesidad y la importancia fundamental que adquiere -para ser justos socialmente con el otro y la otra con quienes nos relacionamos en los procesos de enseñanza-aprendizaje-el diálogo de traducción mutua, que evitaría la colonización en la formación profesional y el ejercicio profesional, si se lo ejercitase e hiciese consciente. Por el contrario, en esas instancias, ese tipo de propuestas rivales a la instrumental aparecen como opciones no creíbles o no confiables y, por lo tanto, son desechadas (Pereyra, 2015). Si no somos capaces de una reflexión crítica sobre él y los Trabajos Sociales, si no somos capaces de entender que lo crítico está indisolublemente vinculado a un proyecto político civilizatorio, a un estar en las luchas desde ese proyecto político, a una praxis construida y co-construida desde la comunidad, si no exploramos y levantamos nuevas epistemologías desde cualquier espacio de lucha, cualquier espacio territorial y/o comunitario, entonces, sí estamos invisibilizando la lucha de los olvidados, de los marginados, de los borrados de la historia, la lucha por las dignidades de la humanidad, por nuestra propia dignidad.

\section{Las dignidades como epistemologías liberadoras de Trabajos Sociales críticos decoloniales}

Lo humano, y la dignidad por extensión, merecen una gran reflexión porque quizá es de los planos más estratégicos y colonizados del Trabajo Social. Su obviedad como prospecto de especie humana, no nos ha permitido cuestionar las contribuciones a la deshumanización de gran cantidad de seres que son afectados por nuestras acciones sociales, aunque nuestra intención ha sido la más loable. Nos ha faltado realizar unas reflexiones más profundas, incisivas que nos permitan indagar sobre los diferentes caminos de ser humanos y los ejercicios de poder de la colonialidad occidental que operan en su constitución. Es claro que con el capitalismo y su desarrollo se operan unas nociones para "humano" y "lo humano" que se materializan en sus realizaciones que, precisamente, los niegan. También que, en un mundo de desigualdad, exclusiones, violencias étnicas o de género el 
de posibilidades de vida digna, los rostros de la mayoría de la humanidad son las caras de los subalternos. Sin embargo, "más allá de las condiciones del vivir humano, tendría que explorarse por las vías de humanización que están presentes históricamente y han sido invisibilizadas con la modernidad" (Cáceres, 2008:2011). Situarnos en el espacio, en el tiempo, en las praxis y en las vivencias del desposeído, del inferiorizado, del desigual, puede contribuir a un compromiso, una acción política de corte liberador en toda una amplia gama, pero en la perspectiva de visibilizar epistemologías otras que ayuden a descolonizar nuestra comprensión de lo social. Implica también, reconocer también en esas mismas humanidades, la semilla de la reproducción del sistema mismo.

Sabemos que como está modelado el mundo no puede producirse una simultaneidad de equidad, de dignidades, pues es el modelo político que económicamente piensa un mundo donde naturaliza que existen desarrollados y subdesarrollados, blancos y negros, donde existen siempre unas sociedades más avanzadas y se impone, con toda la violencia posible, que el ideal de vida es la de ellos, porque eso es lo único posible y que siempre los inferiores, nosotros, estaremos aspirando a alcanzarlos. Es decir, el sujeto colonizado es negado y reproducido como sujeto dentro de la negación que en últimas es una imposibilidad de por vida para ser. Importantes los aportes de Santiago Castro-Gómez en tal sentido (2006). Precisamente, algunos autores han planteado que los Estados de Bienestar Social se han desarrollado de manera diversa a partir del tipo de Estado Nacional y de la relación capital-etnicidad y, nosotros incorporamos el género, o explotación-dominación que se da al interior de dichos Estados (Barreto, 2010). En este sentido, la política social en el Estado Benefactor actuó, no solo con funcionalidad social, económica y política para la preservación de la relación capital-trabajo, sino para la preservación de la relación capital-trabajo-etnicidad-género.

La "cuestión social" o "lo social" a lo que intenta responder el estado cuando elabora y diseña políticas sociales, son respuestas o intentan serlo que responden y se articulan desde la colonialidad del poder, del ser y del estar, por ende, una "cuestión social-colonial- 
eurocentrada". Así, la función social de proveer beneficios para paliar necesidades básicas establece en el plano económico la realización de concesiones mínimas en la redistribución de la renta para contrarrestar el aumento sostenido del costo de vivir, estas concesiones fueron diferentes para países considerados blancos en comparación a los no-blancos, y también lo fueron al interior de estos países para los diversos grupos raciales. De tal manera que la política económica, la política social, la política cultural se ven atravesados por categorías etno-raciales y de inferiorización que mantienen las relaciones de dominación de clase-etnicidad-género y la institucionalidad del capitalismo, el estado-nacional, la familia burguesa y el eurocentrismo. Más allá de estas digresiones, lo central es hacer consciencia de que no es posible aceptar la colonialidad como una estructura de dominación idéntica a sí misma durante más de cinco siglos, ni un pensamiento alternativo que sólo se resiste a ser asimilado y se enfrenta constantemente a las formas de dominación hegemónicas, como plantea Grosfoguel, al explicar estos siglos de dominación de la colonialidad

Tú puedes estar socialmente localizado/a en el lado dominante de una relación de opresión y asumir una perspectiva epistémica desde el lado dominado de dicha relación de poder. De la misma forma, tú puedes estar socialmente ubicado en el lado dominado de una relación de poder y asumir una localización epistémica del lado dominante de dicha relación. Precisamente, el éxito del sistema ha sido hacer que los que están socialmente abajo piensen epistémicamente como los que están arriba (2007: 325).

Los cuestionamientos que surgen es cómo el/los Trabajos Sociales se han asimilado y han sido capaces de reproducir estos discursos sin ser totalmente críticos de los mismos y suponer que con nuestra criticidad es suficiente, que nuestro quehacer logra penetrar las capaz del poder para situar un discurso contrahegemónico o a lo menos anticapitalista de resistencia. Las lecturas permanentes del contexto son recursivas, mecánicamente recursivas, casi esencialistas que buscan posicionarse en un lugar de enunciación situada desde los que hacemos, y con ello fundamos la perspectiva crítica que se 
encuentra presente en los Trabajos Sociales a lo largo de su historia. Quizás en un principio esto pudo dar resultados, especialmente en la reconceptualización, pero esta ilusión fue cada vez con mayor fuerza despojándose de su irrealidad para desnudarse como lo que siempre fue; búsqueda de emancipación, no de liberación. Una de las tantas alternativas, a la cual adherimos, es desprenderse de la idea de totalidad social compacta y concreta creada sólo desde la colonialidad eurocentrada para dar cabida a otras miradas no totalizantes que expresen las heterogeneidades históricas estructurales de las diversas sociedades o una idea de totalidad que albergue la diversidad y contradicciones. "A su vez esta posición política decolonial promueve prácticas cotidianas descolonizadoras de las relaciones sociales, entre estas las establecidas entre géneros, entre grupos étnicos, entre migrantes y no migrantes" (Patiño: 2014:4). Lo diverso es una contravención, un quebrantamiento, no una extensión de libertades individuales o seudo-colectivas, lo diverso es un campo de configuración y reconfiguración social y existencial del cual debemos reaprender acerca de las historias, identidades, comunidades, las familias, las mujeres, la diversidad y las luchas sociales con sus propias particularidades y peculiaridades. Lo evidenciamos en el siguiente esquema:

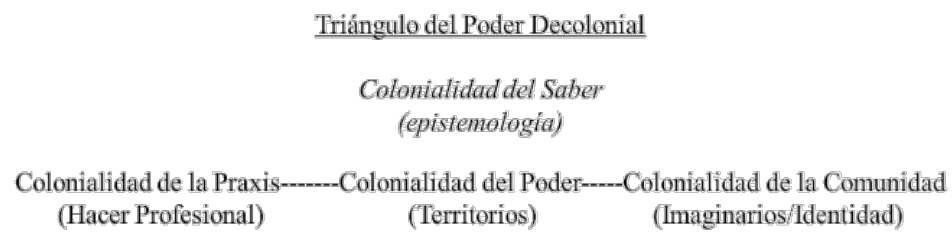

En esta recuperación y reconstitución de lo humano, en la permanencia de la espiritualidad como valor presente en la cotidianidad y en las luchas contra las formas históricas de deshumanización está el gran potencial ideológico, epistémico, político, social, cultural. Es preciso comprender y aclarar que la espiritualidad no es sinónimo de religión, no es misticismo y menos esoterismo ancestral, ello no se corresponde con una visión animista de la naturaleza, sino que 
es una clara respuesta política, es una insurgencia contra lo estrictamente concreto y material. Lo espiritual es un nuevo espacio de lucha como lo demuestra el mundo musulmán, es un territorio en disputa contra poderes históricos establecidos, poderes que pretenden perpetuarse delineando y trasmitiendo una espiritualidad alienante, superflua, basada en el mercado como nueva ortodoxia religiosa e incuestionable basada en el individualismo y la exclusión. Unas otras espiritualidades harían posible recuperar la dimensión femenina de la vida que fue negada y reducida. La espiritualidad es otra forma de alteridad cosmobiocéntrica y Pachacéntrica, es también una respuesta a la crisis civilizatoria que enfrenta la humanidad. Descolonizar el Trabajo Social y transformarlo en "otros Trabajos Sociales” implica, también, asumir la espiritualidad como dimensión activa de lucha y acción que, cuestionada y asumida puede replantear, cualquier noción de ética de las otras humanidades que busquen otras formas de ser y existir del y los Trabajos Sociales que emerjan. Somos conscientes que el Trabajo Social descolonizado involucra procesos y praxis de muy larga duración que superan nuestras transitorias existencias, no obstante, podemos configurar procesos formativos o curriculares con miradas distintas a la tradición eurocentrada establecida, tanto frente a lo humano y lo social. El proyecto descolonial busca dar un giro histórico civilizatorio, por eso no existe un punto de llegada, ni prevalece un esencialismo, ni una fórmula frente a lo que ha de ser. Se construye desde las luchas sociales que se dan también en la academia, con la claridad de la parcialidad y limitación de nuestros saberes situados, en diálogo con todos aquellos que, desde otros lugares, desde otras epistemologías, desde otros saberes luchan por subvertir este sistema colonial eurocentrado patriarcal y racista, con basamentos diferentes para las luchas sociales de liberación. Es importante acercarnos para construir conjuntamente, procesos formativos, conocimientos y luchas liberadoras. "La descolonización no se puede llevar a cabo sin un cambio en el sujeto. Este asunto, está relacionado a lo que otros han denominado como la descolonización de la mente o del imaginario histórico y la memoria" (Maldonado, 2006:72). 
Uno de los elementos ejes de estas luchas es la dignidad, pero no la dignidad colonial eurocentrada, no esa dignidad de la que tanto hablamos y construimos a partir de la modernidad y a la cual le hemos ido quitando su espiritualidad, su realización material y la cual hemos cosificado. La Dignidad en el marco de la modernidad es un concepto al cual se le ha flexibilizado, haciéndolo algo vago, indefinible, singular de un horizonte utópico. Recuperar la dignidad desde lo decolonial es volver a ser, volver a recuperar las memorias, las identidades, las justicias, las voces, los conocimientos, es reconectarse con el nosotros, con la co-construcción comunitaria, con la pluridiversidad. Como dice la tradición quechua: Chaysilloqsimunchisyapamantaaswansumaqkausanampaq ${ }^{51}$. Todas estas praxis liberadoras tienen su raíz en la afirmación de la dignidad y como hemos dicho en otros textos es núcleo gravitante de los Trabajos Sociales críticos. Si el efecto más nocivo de la colonialidad eurocentrada fue y sigue siendo la "deshumanización", la negación de "lo humano", del "otro"; entonces la forma más esencial de un proceso de restitución de la humanidad pasa por aprehender unas epistemologías otras liberadoras para él y los Trabajos Sociales descolonizados, y estas praxis tendrían como contenido la humanización, la afirmación de lo humano, del otro. Afirmar lo "humano" no significa simplemente el reconocimiento de una cierta condición biológica distinta de otras (lo humano distinto de lo animal) sino la afirmación de un universo de relaciones constitutivas de la condición humana (organización cultural, política, económica, social, espiritual, etc.). Pero estos proyectos que buscan una macro transformación no pueden obviar una tarea fundamental, "la descolonización de los cerebros y de los espíritus, la necesidad de revertir centímetro a centímetro la presencia del "enemigo interior", aquél que nos impone el resentimiento, la desconfianza mutua o el mimetismo cotidiano" (Rivera, 2003:14).

Las dignidades como epistemologías liberadoras del y los Trabajos Sociales se diseñan como una actitud. Una actitud que no nos separa

51 "Luego salimos nuevamente a vivir una existencia superior". 
de la historia, sino que nos introduce en ella de diversas formas. Nos convoca -por eso es importante entenderla como un proceso- para comprender la necesidad de "hacernos y restituirnos como humanos" como un proyecto continuo y en constante evolución y transformación. Nos interpela a dejar modos de ser y de pensar colonizados. Nos descompone para llevarnos al verdadero descubrimiento del "otro". Además, nos renueva y hace transitar hacia nuevas esperanzas brindadas todo proceso de transformación. Las dignidades no son otra cosa más que una humanización liberadora colectiva.

La dignidad humana, al igual que muchas de las acciones humanas, han sido y siguen siendo destrozadas por la razón, y particularmente, por la razón instrumental, que está henchida de pretensiones universalistas unívocas y definitivas. Por lo mismo, de la comprensión que se tenga de la naturaleza humana deriva el trato que debe dársele a todo ser que posea dicha naturaleza, a lo que denominamos "dignidad”. Una perspectiva de la dignidad así, sin una determinación clara, sin vocación de valor absoluto o al menos definido es sumamente peligrosa, pues deja al concepto vacío de contenido y difícilmente defendible o sostenible ante los posibles ataques, además de que permite el uso del concepto dignidad de manera ambigua, para argumentar en defensa, por ejemplo, tanto de la legalización como de la prohibición de determinadas situaciones que son objeto de debate como la justicia social, la desigualdad, que son precisamente lo que la colonialidad eurocentrada ha desarrollado con éxito, vaciar de contenido todo lo que pueda ser "peligroso" para el modelo de dominación o lo que busque su transformación, por otra parte, la ha individualizado e instrumentalizado, como sostiene Martínez: "nos ofrece una concepción de la dignidad que surge del apareamiento de dos principios: el auto respeto y la autenticidad; lo que nos lleva a una dignidad humana como producto del propio actuar" (2013:52). Y continúa como desarrollo de la modernidad y la posmodernidad la dignidad asumió una dimensión más amplia al pasar a ser entendida no como un hecho sino como un deber de respeto, con especial importancia social a partir de que se asume como deber de la autoridad del estado el respetar la dignidad (Martínez, 2013:52). 
Se autoproclama una razón completa, acabada y terminante. Ello le lleva directamente a adoptar la idea de totalidad como forma de ordenamiento de la realidad. Su lógica de pensamiento es sencilla: existe un todo que impera sobre las partes que lo componen; las partes sólo existen en relación con la totalidad, a la que están subordinadas. El mecanismo con el que la razón compone la totalidad ordenadora del mundo es dicotómico o división en dos partes: hombre/mujer, razón/sentimiento, conocimiento científico/conocimiento común, civilizado/primitivo, Norte/Sur, por citar algunos ejemplos. La relación dicotómica establece en apariencia una simetría entre cada una de las partes, pero en realidad esconde una relación jerárquica de poder que afecta negativamente a una de las dos, pues la razón metonímica considera que fuera de la dicotomía las partes no pueden ser pensadas ni entendidas al margen del todo (De Sousa Santos, 2009:55-56).

Lo que queremos es entender las dignidades desde los/as humanos/as diversos/as y que ellas y ellos se conviertan en dueños de sí mismos, de sus vidas y sus conocimientos, en oposición consciente a la adopción de un pensamiento ya definido, unilateral y desplazado de su tierra, que diciendo ser completo niega el espacio para la incertidumbre y para lo nuevo, experiencia humana histórica de incompletud. Es haciendo un espacio para conscientemente aprender a ser humano en la construcción de sí mismo, (envuelto en una red de relaciones con otras personas que también se están construyendo), que puede uno descolonizar su pensamiento, su historia, identidad, conocimientos epistemologías, praxis, en otras palabras, Kakllakanchis, runapashamak'upas, orqourmayoqrumipas ${ }^{52}$. Sin embargo, el capitalismo eurocentrado de la colonialidad entiende la dignidad no como parte del todo, como constitutivo de la pacha sino desde una lógica algo esencialista y excluyente, como sostiene cuando plantea que

El término dignidad, por tanto, no designa todos los valores sublimes, sino el valor elevado de un ser que existe realmente como una persona [...] porque todos los seres que en realidad existen y que constituyen la naturaleza tienen algún tipo de valor especial represen-

52 Somos iguales el hombre, la garrapata y el guijarro que rueda de los cerros. 
tado por el termino würde der Kreatur, las entidades no personales no poseen dignidad, propiamente hablando (Seifert, 2014:2)

Las dignidades no son producto del simple hecho que tiene el sentido de ser hombre o mujer singular. Estamos hablando de una(as) dignidad(es) comunitaria(s) que se materializan y fundan en el devenir colectivo. Ninguna dignidad puede pensarse, sentirse, decirse o actuarse al margen de dicho devenir, sino en, con y por él. Este devenir, que debe ser entendido como el devenir de las dignidades comunitarias, traen consigo las configuraciones de una conciencia comunitaria, no en el sentido de que sea un principio originario de realidad, sino más bien el efecto de determinaciones originarias anteriores a ella y de las cuales nos nutrimos. Las dignidades, comprendidas como reciprocidades, se instauran cuando hay otras dignidades, otras formas de ser. De este modo, el mundo de la comunidad tiene que existir antes como comunidad para luego recién existir en la conciencia de la dignidad. Las dignidades de las comunidades se actualizan a cada momento, no se despliegan como ignorancia ni negación de otras dignidades, sino más bien como la inclusión de las mismas. Al tratarse de unas dignidades de carácter siempre incluyente su tipo de dignidad requiere que el yo de todos los seres humanos, sean educados para configurar la memoria y conciencia simbólica de una dignidad, que es otra de las condiciones de posibilidad de la política de vivir bien en comunidad. El límite de este fundamento no es destruir la constitución de los yos-individuales, en ciernes en el hecho de nacer y crecer, y tampoco de establecer nuevos enclaves coloniales sino en educar estas identidades en tanto que, sentidos para cumplir con la reproducción de las conciencias comunitarias, que es el contenido de la conciencia simbólica de las dignidades. Así llegamos a la conclusión de que las dignidades no llevan a preservar la libertad de los seres humanos, sino las dignidades deben ser comprendidas como las libertades de las comunidades. Ninguna identidad puede ser construida sin lazos comunitarios y cabe advertir que los debates frente a las definiciones de la cultura, muchas veces dejan por fuera el poder político que se ejerce frente a lo que se reconoce, lo que se sacraliza y lo que se ignora. "Quien habla del reconocimiento habla de un problema de desigualdad y quien habla de desigualdad habla de 
conflicto e injusticia. Esta es la historia que se prolonga hasta hoy en cuestiones de reconocimiento" (Fornet-Betancourt, 2009:64).

El problema de trabajar los discursos únicamente sobre las evidencias, y la dignidad se ha transformado en una de ellas, es que efectivamente sostienen la vigencia de los metarrelatos modernos. La desigualdad social a la que tanto refiere la Unesco es naturalizada, deja a libre determinación el asunto de la exclusión y no se esfuerza por aclarar las responsabilidades y las interpelaciones que sobre lo humano generan (Cullen, 2008). Son estas perspectivas que, aunque parecen bien intencionadas, sólo confunden y caemos en su lógica de la comprensión de lo social basado en cuestiones como totalidad social, historicidad, contradicción, transformación, que luego repetimos y no reflexionamos su contenido ni origen. Sería interesante ampliar las miradas porque lo local, las subjetividades y la vida cotidiana, aunque se pueden advertir manifestaciones de la desigualdad social, también pueden fundamentar la comprensión crítica de lo social, "porque eso llevaría también a repensar el asunto de la transformación” (Molina, 2012:108), y no porque la realice sólo el Trabajo Social, es ilusorio pensarlo, sino porque el ideal humano continúa vigente en su validez "la necesidad de reexaminar la misión de la profesión, la formación profesional, el replanteamiento del concepto de transformación como fin último de la profesión desde la perspectiva ideológica y práctica" (Guardiola Ortiz y Rivera, 2012:283).

Es urgente y crítico hacer un giro, es decir, lograr la apertura, la libertad del pensamiento, de formas de vida-otras (economías otras, teorías políticas-otras), nuevas dignidades, nuevas humanidades, como sostiene Mignolo: "la limpieza de la colonialidad del ser y del saber; es el desprendimiento de la retórica de la modernidad y de su imaginario imperial articulado en la retórica de la democracia. (2008:253). De ellas debemos aprender, con ellas debemos ser, con ellas co-construimos humanidades y dignidades. Esto significaría co-construirnos en una perspectiva crítica permanente para fortalecernos en nuestras posibilidades dialógicas con otras/otros, con otros saberes, con otras identidades e historias, principalmente, para construir y co-construir conjuntamente otros ideales de vida por los cuales luchar. Desvelar, 
denunciar la individualización de los sujetos, la promoción de la autonomía y la libertad en donde sobresale principalmente la ruptura con los lazos sociales, la trasmutación y flexibilidad de las identidades, la naturalización de dualismos (tradicional/moderno, ruralidad/urbano u otros), la complicidad en la construcción de subjetividades de la colonialidad eurocentrada que contribuyen a la fragmentación social, a la desaparición de formas de resistencia, a la destrucción de poderes comunales y, que finalmente, contribuyen al desarrollo y mantención del sistema capitalista en los escenarios cotidianos y públicos.

Este develar, desmontar y denunciar debe abarcar los planos objetivo, subjetivo e intersubjetivo, que nos indican, señalan y convencen cuáles son nuestras aspiraciones de vida que se expresan y se materializan en los programas sociales, en los procesos de formación, en nuestro ejercicio profesional y en las reivindicaciones de lo diverso: "Lo local viene a representar una forma de localización y reducción en la cartografía mundial del saber y del ser y mantener así la "desautorización cognitiva de pueblos y culturas por todo el planeta" (FornetBetancourt, 2009:18). En términos parecidos, es lo que se ha hecho con los saberes de los pueblos originarios, su grave instrumentalización al adscribírsele una perspectiva conservacionista poco coherente con la cosmología que le acompaña relacionados con la animalización del humano y la humanización de las plantas y los animales, su complementariedad y correspondencia mutua y recíproca (Cáceres, 2008). Las dignidades como nuevas epistemologías son unos virajes en plena transición que nos coloca ante el reto de contribuir al desarrollo de un análisis de la colonialidad y de la dignidad, ya no como fenómeno sino como episteme intrínseca de la colonialidad eurocentrada y sus proyectos liberadores. La apuesta obliga a abandonar y cuestionar activamente esta pretensión de unidad universalista en la opresión. Para ello podemos y requerimos articularnos y comprometernos con los movimientos autónomos, con las comunidades, con la restitución de genealogías perdidas que señalan la posibilidad de otros significados de interpretación de la vida y la vida colectiva, que otras humanidades son posibles. Como presentamos en el siguiente esquema. 
Descolonizaciones

Praxiológicas

(Profesional)

\section{Espiral del Poder Decolonial}

Descolonialidades del Ser-Saber-Vivir (Epistemologías)

Descolonizaciones

De las Dignidades (Acción Profesional)

Descolonizaciones

Liberadoras

(Comunitaria/Personal)

Él y los diversos Trabajos Sociales necesitan realizar una ruptura con la dependencia colonial en sus saberes pues su liberación puede provenir, también, de sus propias vinculaciones con los sectores sociales que justifican su existencia profesional. Catherine Walsh argumentaba que las ciencias sociales pueden y deben ser repensadas desde una pluriversalidad epistemológica que tenga en cuenta y dialogue con las formas de producción de conocimientos que se generan en ámbitos extra académicos y extra-científicos (2007:102). La defensa y reconocimiento del conocimiento local implica reconocer las fuentes del saber, las ideologías que subyacen en éste, su carácter ancestral, su adaptación y recreación en el contexto moderno. Es una invitación a que imaginemos un(os) Trabajos Sociales Otro(s) que aprenden de los sentidos de vida, de la política, la organización y de todo lo que se ubica como resistencia sin que logre tener un carácter dialógico con las supuestas grandes teorías. Es urgente el saber situado como práctica de conocimiento, reconocer el lugar de enunciación en diálogo con la historia, espacio y tiempo en que se conoce, es decir, Taqpachaniqhispiyasipxañan ${ }^{53}$.

\section{(In)conclusiones}

América Latina atraviesa por un periodo nuevo en su reflexión teórica e intelectual, orientado a la fundamentación de unas ciencias sociales y unos saberes críticos acordes con los tiempos de resistencia y liberación protagonizados por la diversidad social, cultural, episté-

53 Liberémonos todos. 
mica, política que los contiene. Hoy estamos viviendo una verdadera confrontación civilizatoria, donde podemos observar de manera más evidente el estado actual en referencia a la crisis y agotamiento del modelo hegemónico de poder que también opera en las ciencias sociales, modelo construido desde la colonialidad eurocentrada y la actualización de diferentes expresiones del pensamiento crítico, pero igualmente, como diría de Sousa, se trata de una transición de la cual no sabemos exactamente a dónde vamos. Lo prometedor y desafiante es que se trata de una confrontación abierta e incierta, cuyo rumbo parece cada vez más atado al destino mismo de las luchas de resistencia protagonizadas por las multiplicidades sociales de nuestra América. Por eso la importancia y la actualidad de este tipo de espacios y de escenarios de discusión académica, social, profesional porque han aparecido nuevos elementos, no sólo desde el punto de vista de las ciencias sociales, sino también nuevos elementos desde el punto de vista de las realidades de América Latina, para nuestro caso particular una realidad surcada no sólo de campesinos y obreros, sino que desde todos los subalternizados. Para reconstituir nuestra vida necesitamos impulsar acciones en muchas dimensiones: locales, nacionales e internacionales; emerger de una conciencia comunitaria para el buen vivir; comprender que debemos empezar por integrarnos a todo y a todos, que necesitamos acercarnos a los demás. En este proceso de entendimiento de nosotros y de los demás no hay un primer paso seguido de un segundo, es una interacción permanente, pues una reflexión interna inmediatamente genera una repercusión externa; más aún: es simultánea. Así iremos dialogando y reencontrándonos.

Debemos olvidar los sueños, abandonar nuestras viejas creencias y nuestras amistades de antes. No perdamos el tiempo en estériles letanías o en mimetismos nauseabundos. Dejemos a esa Europa que no deja de hablar del hombre al mismo tiempo que lo asesina dondequiera que lo encuentra, en todas las esquinas de sus propias calles, en todos los rincones del mundo (Ticona, 2005:157).

Pero queremos caminar, transitar permanentemente, todo el día y todos los días, en compañía de la humanidad, de todas las humanidades. Se trata de no extender los silencios, la mudez porque entonces, 
cada una de nosotras y nosotros apenas percibimos al que está al lado, al que está delante y como humanidades no nos reconocemos, nos encuentran cada vez menos, nos hablamos cada vez menos. Se trata de reiniciar una historia planetaria que tome en cuenta la humanidad. Pero si deseamos que la humanidad avance con audacia, si queremos elevarla a un nivel distinto del que le ha impuesto la colonialidad eurocentrada, entonces hay que inventar, hay que descubrir, hay que recuperar. Si queremos responder a la esperanza de nuestros pueblos, no hay que fijarse sólo en aquel sino en nosotros, en todos, pues sólo entre todo lograremos recuperar y resituar la dignidad, la libertad, nuestras identidades, nuestros sentires, volver a estar y ser con la pacha.

Nuestras prácticas personales y profesionales en Trabajo Social indican a cada instante que las luchas no representan distintas y opuestas estructuras de poder, son parte de una gran lucha planetaria en las que las estructuras de poder no nos dejan lugar nada más que a la sumisión, entonces, la lucha por nuevas dignidades pasa por traernos nuevas praxis, nuevas epistemologías, recuperar nuestras memorias, nuestras historias. Implica unas nuevas lecturas descolonizadas de los imaginarios, representaciones sociales, prácticas cotidianas de los grupos con quienes trabajamos, pero también implica insistir en que necesitamos develar y decolonizar nuestros propios imaginarios y prácticas como trabajadoras y trabajadores sociales. Sin embargo, abogar por la necesidad de fortalecer un "Trabajo Social latinoamericano" barriendo con el pensamiento occidental tal como fue propuesto en el periodo de la reconceptualización y como ha sido reposicionado en la actualidad (Hermida y Meschini, 2012), sólo sería reemplazar una totalización por otra. Estamos transitando de una colonialidad del poder, del ser, del estar que se ha vuelto incierta hacia otra propuesta civilizatoria comprometida con las necesidades de transformación y liberación de las realidades latinoamericanas. Cuando consolidemos estas nuevas miradas civilizatorias, construidas con estas nuevas dignidades, entonces, y sólo entonces podremos hablar de pensamiento y de ciencias sociales, también de Trabajo Social, latinoamericanas, africanas, asiáticas. Es necesario reflexio- 
nar que mientras las praxis del Trabajo Social continúen formando parte de la estrategia de mostrar una palabra liberada de los dispositivos de normalización y disciplinamiento, el Trabajo Social seguirá sosteniendo esa especie de indignidad de hablar por los otros. El futuro delos Trabajos Sociales no es sólo la reflexión teórica desde el ejercicio práctico sino que, tiene que ser marcada por actitudes que aboguen por defender aquellas pluriversalidades que son liberadoras, estamos llamados a trabajar con y desde lo colectivo-comunitario y una de nuestras principales preocupaciones en este contexto es coconstruir a través de la sensibilización, del respeto, la aceptación de las diferencias, de que nuestras praxis son las praxis de las comunidades, de las personas, son ellas quienes la crean, quienes las desarrollan, quienes las viven.

En ese sentido, el Trabajo Social debe formarse, co-construirse desde una perspectiva que tenga la valentía de combatir la colonialidad eurocentrada, es decir, estar muy atento para poder mirar y escuchar el grito, muchas veces silencioso, silenciado, impronunciable, de miles de personas abrumadas y derrotadas por el modelo de dominación. Buscar significados en común, discutir, problematizar estos planteamientos, permite construir alternativas entre todas y todos, para reinventar el Trabajo Social con posibilidades de elaborar, desarrollar, praxis liberadoras, dignidades liberadoras con y desde diversos sectores populares del Sur.

\section{Referencias bibliográficas}

Adao, A. (2011). La esperanza viene del sur. En Para un pensamiento del sur: diálogos con Edgar Morin. Río de Janeiro, Brasil: SESC, Departamento Nacional.

Alhaj, A., \& al., e. (2013). Social workers in comparitive perspective. En Wales and South West England Social Worl Doctoral Conference. Inglaterra: University of Bristol.

Barreto Cortez, E. (mayo de 2010). Desafíos de la formación antirracista en Trabajo Social. Obtenido de Boletín Electrónico Surá Número 166: http://www.ts.ucr.ac.cr/ binarios/sura/sura-0166.pdf

Cáceres, M. (2008). Concepciones del ser humao y vías de humanización en las culturas del Abya Yala. En R. Fornet Betancourt, Concepciones de ser humano e 
interculturalidad. Culturas de humanización y reconocimiento. Aachen, Alemania: Verlag Mainz.

Castro Tavara, M., \& V., C. C. (2012). El Trabajo Social en Perú. En M. Melano, \& D. J.P., El Trabajo Social Latinoamericano (págs. 249-265). Buenos Aires, Argentina: Lumen Hvmanitas.

Castro-Gómez, S. (2006). La Hybris del Punto Cero. Ciencia, raza e ilustración en Nueva Granada (1750-1816). Bogotá, Colombia: Pontificia Universidad Javeriana.

Cullen, C. (2008). “¿Cómo podemos hablar de concepciones y rostros de lo humano en un mundo de exclusión y desigualdad? En R. Fornet Betancourt, Concepciones de ser humano e interculturalidad. Culturas de humanización y reconocimiento (págs. 363366). Aachen, Alemania: Verlag Mainz.

De Sousa Santos, B. (2009). La Universidad en el siglo XXI. Para una reforma democrática y emancipatoria de la universidad. Cochabamba: Miño y Dávila.

Fornet Betancourt, R. (2009). Tareas y propuestas de la filosofía intercultural. Aachen, Alemania: Verlag Mainz.

García, F., \& Roca, P. (2017). Pachaqutek: Una aproximación a la cosmovisión. Venezuela: Fundación Editorial El perro y la rana.

Grosfoguel, R. (2007). Diálogos decoloniales con Ramón Grosfoguel: transmodernizar los feminismos. Entrevista realizada por Doris Lamos Canavate. Tabula Rasa Número 7, 323-340.

Guardiola Ortiz, D., \& Rivera, A. (2012). El Trabajo Social en Puerto Rico. En M. E. Hermida, La investigación y la práctica en Trabajo Social (págs. 267-293). Bogotá, Colombia: Universidad Nacional de Colombia.

Guattari, F. (1998). De un signo a otro. Artefacto Número 6.

Hermida, M. E., \& Meschini, P. (2012). Pensar en invertir en la cuestión social: el Trabajo Social desde un enfoque poscolonialista. En L. Catelli, \& M. Lucero, Términos claves de la teoría poscolonial latinoamericana: despliegues, matices, definiciones. Rosario: UNR Editora.

Lavaletta, M., \& Ioakimides, V. (2011). International social work or social work internationalism? Bristol: The Policy Press.

Maldonado, N. (2006). La descoloniazión y giro-descolonial. Comentario Internacional Número 7.

Martinez Bullé-Goyri, V. (2013). Reflexiones sobre la dignidad humana en la actualidad. Boletín Mexicano de Derecho comparado, 39-67.

Mignolo, W. (2008). La opción descolonial: desprendimiento y apertura. Un manifiesto y un caso. Tabula Rasa Número 8, 243-281. 
Molina, M. (2012). El Trabajo Social en Costa Rica. En M. Melano, \& D. J.P., Trabajo Social Latinoamericano. Buenos Aires, Argentina: Lumen Hvmanitas.

Munro, E. (2011). The Munro Review of Child Protection: Final Report. Recuperado de: http://www.official-documents.gov.uk/document/cm80/8062/8062.pdf.

Patiño, M. (2014). La Feminización de la Migración: experiencias e historias de vida de mujeres migrantes, representaciones sociales e imaginarios, una lectura desde el Feminismo Descolonial, tesis doctoral. Costa Rica: Facultad de Ciencias Sociales.

Pereyra, E., Verón Ponce, B., \& Páez, C. (2013). Entre lo Asistencial y lo Socioeducativo en el Trabajo Social. I Congreso Internacional de Ciencias Sociales y HumanidadesVIII Encuentro interdisciplinario de Ciencias Sociales y Humanidades-Perspectivas y Debates actuales a 30 años de la democracia (págs. 8-10). Córdoba, 20,21 y 22 de noviembre de 2013: Recuperado de: http://conferencias.unc.edu.ar/index.php/ponencias/ ponencias2013/paper/view/1883/382.

Quijano, A. (2014). Colonialidad del poder, eurocentrismo y América Latina. En Cuestiones y horizontes: de la dependencia histórico-estructural a lacolonialidad/ descolonialidad del poder. Buenos Aires, Argentina: CLACSO.

Rivera Cusicanqui, S. (2014). Oprimidos, pero no vencidos. La Paz, Bolivia: Aruwinyiri/ Yachaywasi.

Seifert, J. (2014). Dignidad humana: dimensiones y fuentes en la persona humana. Liechtenstein: Internationale Akademie für fhilosophie im fürstentum Liechtenstein.

Ticona, E. (2014). Lecturas para la descolonización. Cochabamba, Bolivia: Plural Editores.

Walsh, C. (2007). ¿Son posibles unas ciencias sociales culturales otras? Reflexiones en torno a las epistemologías. Nómadas Número 26, 1

Recepción: 24/07/2018

Aceptación: 07/07/2019 